This is an Accepted Manuscript of an article published by Taylor \& Francis Group in Vehicle System Dynamics on Jun/06/2018, available online:

https://www.tandfonline.com/eprint/Wf47PYHelDEbVEKC5T8 U/full?target $=10.1080 / 00423114.2018 .1480787$ 


\title{
Failure Mode and Effects Analysis of Dual Leveling Valve Airspring Suspensions on Truck Dynamics
}

\author{
Yang Chen, Graduate Research Assistant \\ Yunbo Hou, Graduate Research Assistant \\ Andrew Peterson, Senior Research Scientist \\ Mehdi Ahmadian, Dan Pletta Professor and Director \\ Center for Vehicle Systems and Safety \\ Virginia Tech, MC-0901 \\ Blacksburg, VA 24060
}

\begin{abstract}
Failure mode and effects analysis (FMEA) are performed for a dual leveling valve pneumatic suspension to determine the effect of suspension failure on tractor-semitrailer dynamics, using a detailed model of suspension pneumatics coupled with a truck dynamic model. A key element of failure analysis in suspensions with one or two leveling valves is determining the effect on the vehicle body roll when one or more failures occur. The failure modes considered are mainly the suspension pneumatic components, including clogged leveling valve, bent control rod, disabled leveler arm, and punctured or leaking connectors and pipes. The pneumatic suspension is modeled in AMESim, with critical parameters established through component testing. Upon validating the AMESim component model experimentally, the pneumatic suspension model is integrated into TruckSim for studying the consequences of suspension failure on truck dynamics. The simulation results indicate that the second leveling valve in a dual-valve arrangement brings a certain amount of failure redundancy to the system, in the sense that when one side fails, the other side can compensate for the failure. Equipping the trailer with dual leveling valves brings an additional stabilizing effect to the vehicle in the event of tractor suspension failure.
\end{abstract}

Page 2 of 25 


\section{Introduction}

Pneumatic suspensions are used extensively on highway semi-tractors and trailers to provide better handling and a softer ride [1-2]. In general, the pneumatic suspension requires a load-leveling mechanism to maintain the truck's intended ride height for widely varying loads that occur in loaded, unloaded, and bobtail conditions [3]. The load-leveling mechanism typically consists of many pneumatic components such as the leveling valve(s), the regulator valve(s), the air tank, the air pipes, and fittings. These components can be combined in different configurations that include employing one or two leveling valves. The schematic in Figure 1a depicts the plumbing configuration for a suspension with one leveling valve on a tractor's tandem axle. The same suspension configuration is also applicable to trailers with a tandem axle. This type of suspension referred to here as "original equipment (OE) suspension" is commonly used, mainly due to its lower cost and easier installation advantages. Figure $1 \mathrm{~b}$ presents an alternative plumbing configuration with dual leveling valves and a symmetric pneumatic circuit, which has proven to be better suited for controlling the roll and pitch dynamics of the truck [4-6]. This study refers to this configuration as "balanced-air (BA) suspension". The BA suspension is designed to provide an independent and balanced side-to-side roll control through balanced pressure and well-regulated airflow. The independent control yields a variable roll stiffness that increases with increasing body roll to improve the roll stability and safety of the vehicle, even though it might cause a slight increase of fuel consumption due to a higher use of compressed air. It is estimated that the air consumption will be approximately 3-5\% higher, based on empirical data from our initial tests. Test data [4] has shown that a truck with the BA suspension experiences less body roll and a faster return to leveled orientation during dynamic maneuvers than a truck with the $\mathrm{OE}$ suspension. The basic principle of the BA suspension is that in response to body roll, air pressure (airspring force) on the jounce side increases, while simultaneously the air pressure (airspring force) on the rebound side decreases, resulting in balanced suspension forces to perfectly level the truck body [7]. One potential benefit of the BA suspension is that even when one side fails, the other side still works as intended to balance the truck body. In addition, if either the tractor or trailer Page 3 of 25 
encounters a suspension failure, the other unit provides an additional stabilizing effect to compensate for the failure.

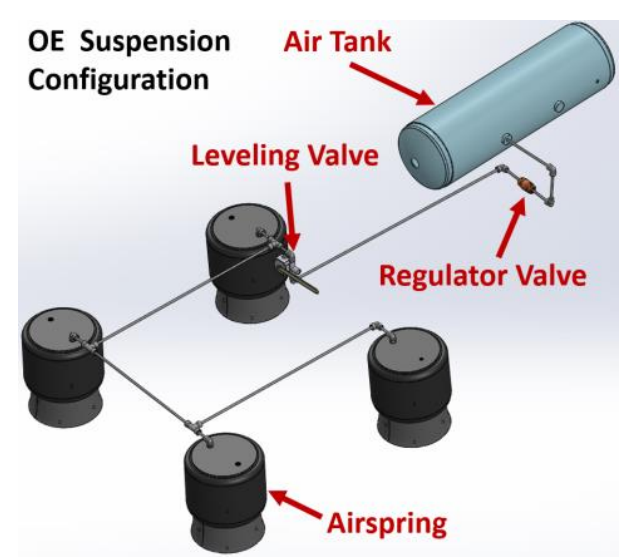

(a)

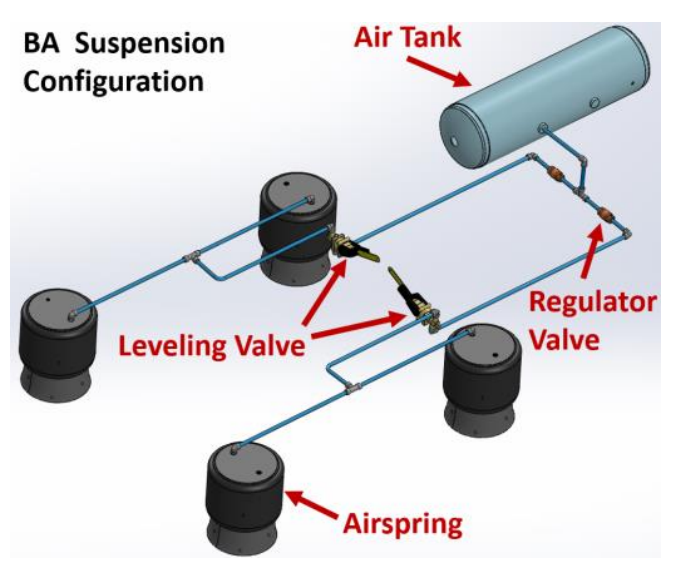

(b)

Figure 1. (a) Original equipment and (b) balanced suspensions on a semi-tractor tandem axle.

The present paper provides simulation-based failure effect analyses of pneumatic suspensions. A multi-domain dynamic model is prepared, which has been very useful in attaining a better understanding of suspension dynamic responsiveness and truck roll behavior under any pneumatic component failure, including the prediction of dynamic response for different suspensions. The pneumatic suspension system is broken down into component levels to identify the potential failure of each component, including its causes and effects [8], resulting in a failure mode and effect table. Based on the table, three representative failure modes are determined and modeled. Airspring and leveling valve models are validated by simulation or experimental data. The developed pneumatic suspension model is then coupled with a single-trailer truck (WB-67) dynamic model in a co-simulation platform. The multi-domain model is used to study the performance of the BA suspension on resisting the roll motion of the tractor and semi-trailer when one of the failures occurs. The simulation results of the BA suspension are compared with the OE suspension, for all failure cases, in terms of the mass flow rate through the leveling valve, the vehicle body roll, and the suspension dynamic response. The paper concludes with a discussion of simulation results. 


\section{Failure Cause and Effect Studies for a Semi-truck Pneumatic Suspension System}

This section mainly describes how to recognize various failure modes of a truck pneumatic suspension and determine their effects. The pneumatic suspension system for the heavy truck application consists of many pneumatic components; therefore, it is necessary to identify the failure mode for each element/subsystem and to categorize the various failure effects [8]. As shown in Figures 2a and 2b, the pneumatic suspension components included in the analysis are:

- Leveling valves

- Air fittings (tee connector, elbow connector, etc.)

- Air pipes

- Regulator valves

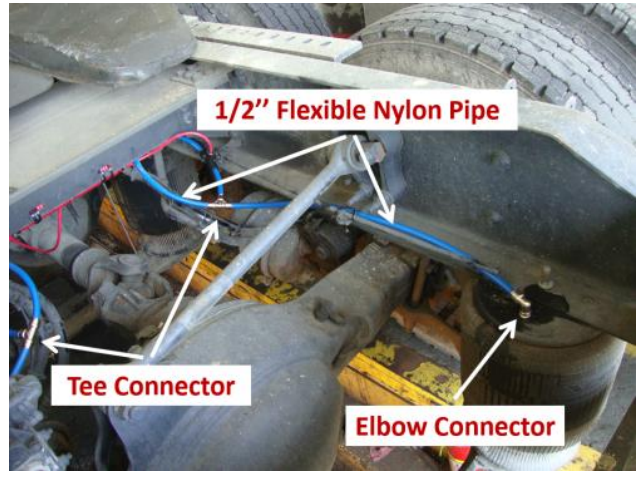

(a)

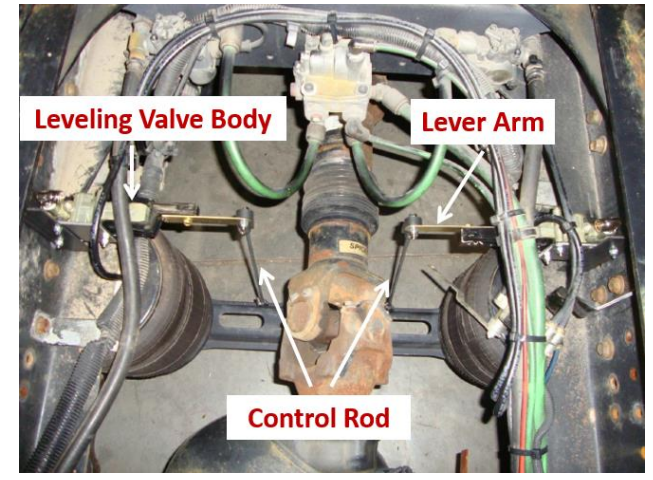

(b)

Figure 2. Pneumatic suspension system: (a) air fitting and air pipe and (b) leveling valve.

The potential failures of the components and their causes are determined as follows:

(1) Failure modes of the leveling valve: three failure modes are assigned to the leveling valve:

- The leveling valve clogging: air impurities can clog the flow path of the leveling valve for inflation, deflation, or both. In the last case, no air is supplied to or dumped from the airsprings through the leveling valve.

Page 5 of 25 
- The control rod detachment: this failure takes place when the control rod of the leveling valve disconnects from the lever arm, or the control rod is broken. This failure causes the leveling valve to completely lose the ability to respond to suspension deflection. This failed leveling valve stays closed at all times, keeping the mass of air within the airsprings constant.

- The control rod bending: the bent control rod results in pulling down the lever arm to deflate the airsprings. This failure will decrease the ride height. The same failure effect can also occur due to a bent bracket that is used to attach the control rod to a designated axle.

(2) Failure modes of the air fittings: the air fittings that are used for the pneumatic suspension include tee connectors, elbow connectors, straight union connectors, among others. The most common failure mode for the air fittings is cracking due to excessive air pressure or aging. Any these failure modes will result in an air leakage at the cracking point.

(3) Failure modes of the air pipes: the failure for the air pipes is considered to be a rupture, leading to an air leakage in the system. Although the air pipes are rated for high-pressure applications, it is still likely for failure to occur due to fatigue and rotting. The air leakage of air fitting and pipes is also attributed to incorrect assembly procedure and poor installation which are, however, not considered as failure modes.

(4) Failure modes of the regulator valve: clogging occurs due to debris being jammed inside the valve. The likelihood of this failure is relatively low because the air supplied by the compressor is filtered, and the flow area of the regulator valve is designed to be considerably larger than components such as the leveling valve. Therefore, the failure of the regulator valve is not included in this investigation.

Table 1 summarizes the potential failure modes and effects of each pneumatic suspension component, as discussed previously. The failure modes are studied as one case in this paper if they provide identical failure effects. For example, the suspension system air loss is one

Page 6 of 25 
study case that represents all related failure modes. For this study, three representative failure cases are identified:

- Fully-blocked leveling valve (no air flow)

- Bent control rod of the leveling valve

- Suspension system air leakage

Table 1. Excerpts of FMEA showing the progression of failure modes and effects for the pneumatic suspension components.

\begin{tabular}{|l|l|l|}
\hline Part name & Potential failure mode & Potential failure effect \\
\hline \multirow{2}{*}{ Leveling valve } & Blocked leveling valve & $\begin{array}{l}\text { No air supplied to or dumped out of the } \\
\text { airspring on the failed side (Note: The } \\
\text { control rod detachment causes no air } \\
\text { flow in and out of the airspring.) }\end{array}$ \\
\cline { 2 - 3 } & Detached control rod & Lower ride height on the failed side \\
\cline { 2 - 3 } & Bent control rod bends & Suspension system air leakage \\
\hline $\begin{array}{l}\text { Push-to-connect air } \\
\text { fitting (elbow, } \\
\text { straight, tee, etc.) }\end{array}$ & Mechanical rupture & \\
\hline Flexible nylon pipe & Rupture & \\
\hline
\end{tabular}

\section{Pneumatic Suspension and Truck Dynamic Simulation Model}

The effects of the three representative suspension failures on the truck roll dynamics are evaluated through modeling and simulation. This section introduces the modeling of the fluid dynamics of the pneumatic suspension, which is coupled with a WB-67 truck dynamic model for this study.

\subsection{Pneumatic Suspension Model}

\subsubsection{Airspring Model}

Based on the First Law of Thermodynamics, the airspring's temperature variation as a function of time can be defined as follows:

$$
\dot{T}_{s}=\frac{\gamma-1}{R m_{s}}\left[\dot{m}_{s} h_{i n}-\frac{R T_{s}}{\gamma-1} \dot{m}_{s}+k_{a s} S_{a s}\left(T_{e x t}-T_{s}\right)-P_{s} \dot{V}_{s}\right]
$$

Page 7 of 25 
where $P_{S}, T_{S}$, and $V_{S}$ are, respectively, the pressure, temperature, and volume of the air in the airspring [9-13]. $\mathrm{R}$ and $\gamma$ are the specific gas constant and the specific heat ratio. $k_{a s}$ and $S_{a s}$ are the thermal exchange coefficient and the thermal exchange area. $T_{\text {ext }}$ is the ambient temperature, and $h_{\text {in }}$ represents enthalpy per mass unit flowing into the airspring. Using the perfect gas law and continuity equation yields:

$$
\dot{P}_{S}=\frac{P_{s}}{T_{s}} \dot{T}_{S}+\frac{R T_{s}}{V_{s}} \dot{m}_{S}-\frac{P_{S}}{V_{s}} \dot{V}_{S},
$$

where $\dot{T}_{S}, \dot{P}_{S}, \dot{m}_{s}$, and $\dot{V}_{S}$ are the rate of change of the airspring's temperature, pressure, mass, and volume with time. In Equations (1) and (2) that govern the dynamic behavior of the airspring, $\dot{m}_{s}$ and $h_{\text {in }}$ are determined by the air flow across the leveling valve. The thermal exchange area, $S_{a s}$, can be calculated from the measured geometric data of the airspring; the thermal exchange coefficient is adjusted through the comparison between simulation and experimental results. The time change of the airspring volume is defined as:

$$
\dot{V}_{s}=\frac{d V}{d x} \dot{x},
$$

where $x$ is the suspension deflection that depends on vehicle dynamic response. The experimental results of the change of airspring volume with respect to height are shown in Figure $3 \mathrm{a}$. The airspring force is calculated by multiplying gauge pressure and effective area as:

$$
F_{s}=P_{g} A_{e},
$$

The gauge pressure in the airspring is defined as the absolute pressure minus the atmospheric pressure:

$$
P_{g}=P_{s}-P_{a t m},
$$

In Equation (4), $A_{e}$ is the effective area of the airspring, which is determined experimentally as a ratio of measured force and pressure. Figure $3 \mathrm{~b}$ shows the experimental Page 8 of 25 
results of the effective area at different airspring heights for initial pressures of 15 and 20 psi. As can be observed, the effective area of the airspring changes nearly independently of pressure, but is affected by the airspring height variation [13-14].

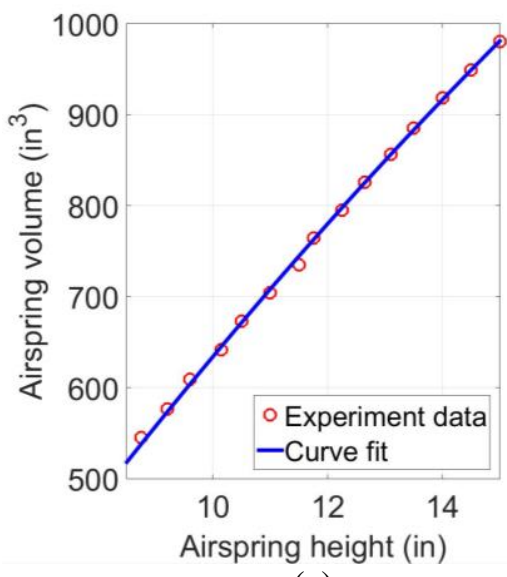

(a)

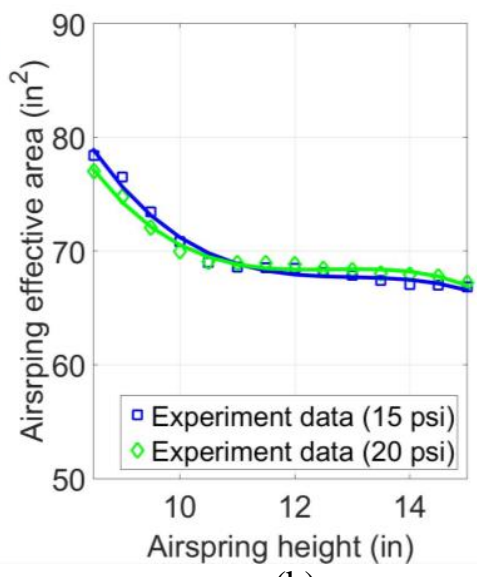

(b)

Figure 3. Experimental characterization of (a) airspring volume and (b) airspring effective area.

With the experimental characterization obtained, a physical representation of the airspring dynamics is considered using AMESim, as shown in Figure 4a. The dynamic simulation procedure of the airspring model is presented in Figure 4b. To validate the AMESim airspring model for solving the differential equations that govern the airspring dynamic behavior, another model is developed in Simulink, according to Equations (1) and (2). The details of the model are included in Appendix A (Figure 17). Figure 5 compares the pressure and temperature results of the AMESim model with the Simulink model for a sinusoidal excitation across the airspring at $0.25 \mathrm{~Hz}$ and 1-inch amplitude. The results in Figure 5 show the agreement between the physical model in AMESim and the mathematical representation of the airsprings in Simulink. This provides us with confidence that the AMESim model closely matches the ideal gas principles as given in Equations (1) and (2).

Page 9 of 25 


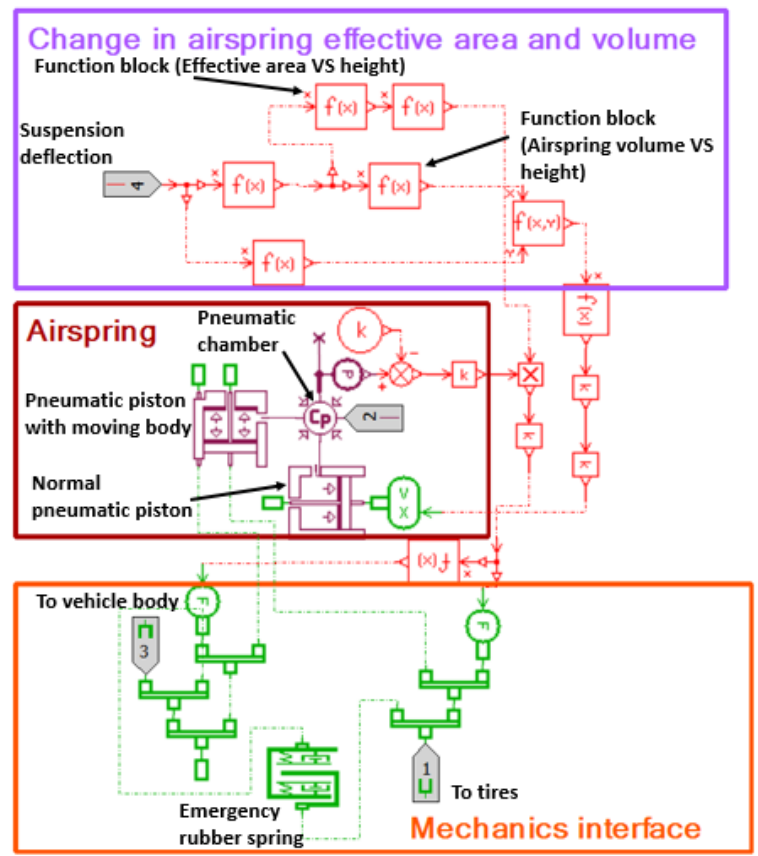

(a)

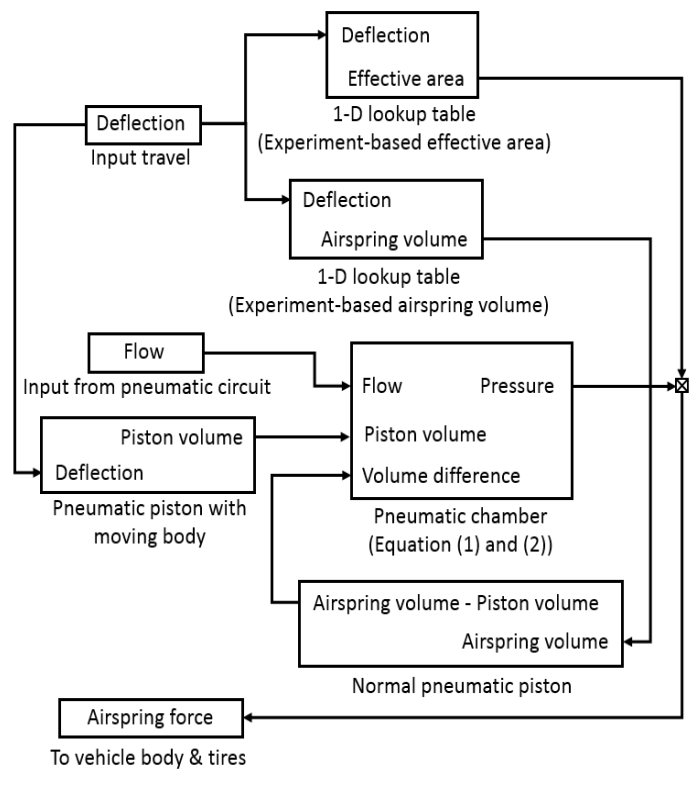

(b)

Figure 4. (a) Schematic of airspring model in AMESim and (b) dynamic simulation procedure of the airspring model.
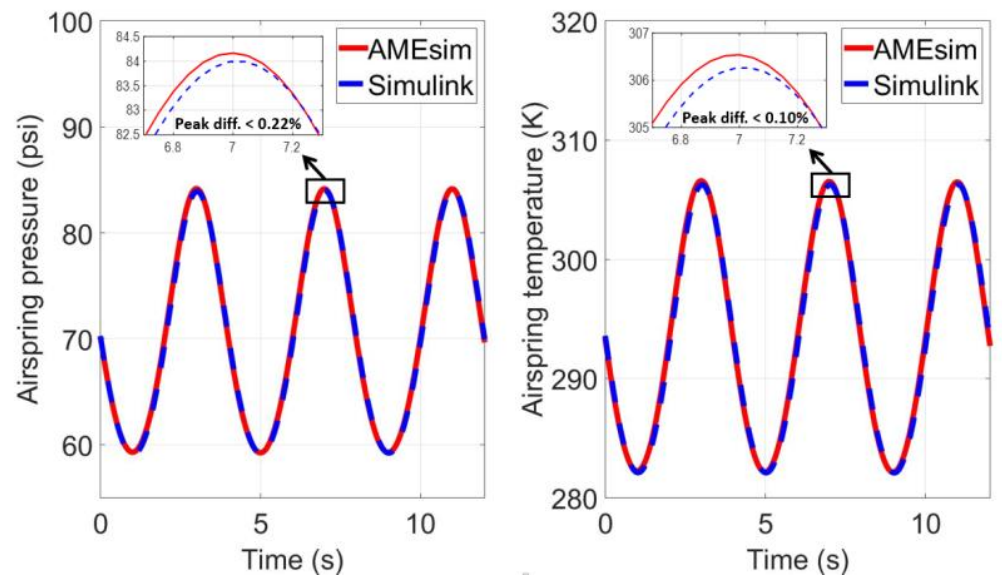

Figure 5. Comparison results between AMESim and Simulink models for airspring pressure and temperature when subjected to a 1 -in sinusoidal excitation at $0.25 \mathrm{~Hz}$.

Next, it is necessary to evaluate the thermodynamic effect of the AMESim airspring model.

Figure 6 shows a comparison of airspring force in simulation and experiment for a 1-inch sinusoidal excitation across the airspring at $0.1,0.5$, and $1.0 \mathrm{~Hz}$. The comparison between the simulated and the experimental results confirms the validity of the thermodynamic model of the airspring. Figure 6 indicates smaller hysteresis at higher frequencies, due to 
the shorter time cycle associated with high frequencies. This is mainly due to less heat transfer through the bellow at shorter time cycles.
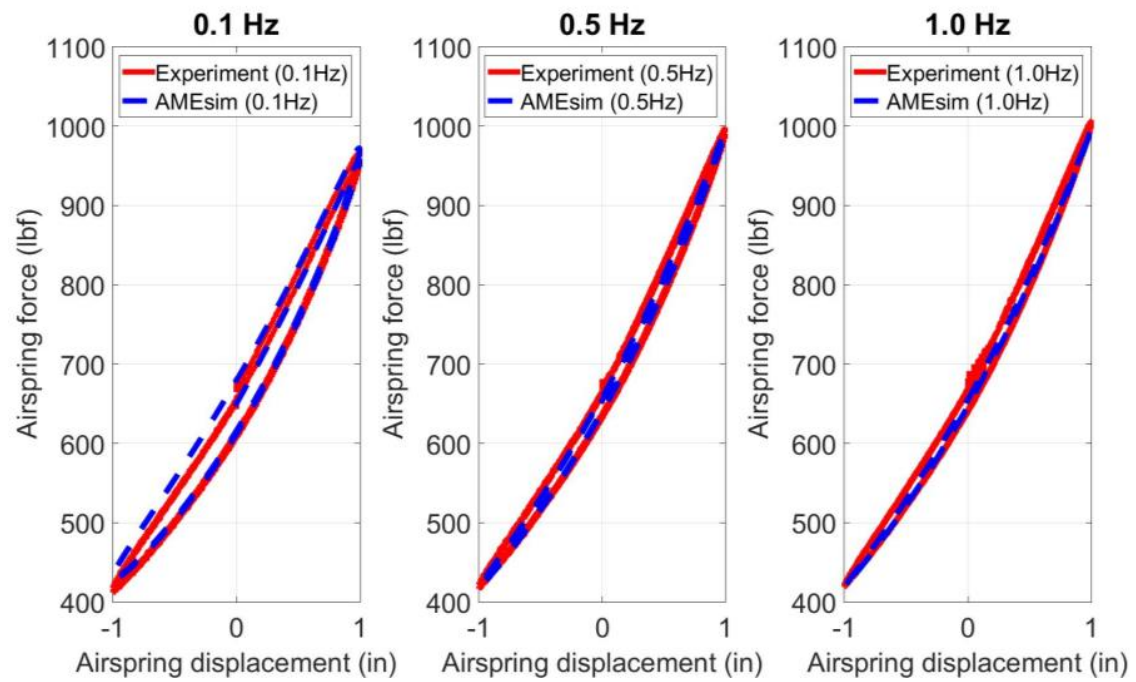

Figure 6. Airspring force response for sinusoidal excitation at $0.1 \mathrm{~Hz}, 0.5 \mathrm{~Hz}$, and $1.0 \mathrm{~Hz}$ (initial airspring pressure is $10 \mathrm{psi}$ ).

\subsubsection{Leveling Valve Mode}

The leveling valve is typically mounted to the vehicle frame and provides a lever arm attached to the axle via the control rod, as shown in Figure 7a. If the truck body sinks due to added loads, the lever arm rotates up allowing the pressurized air in the air tank to enter the airsprings through the leveling valve (air charging) until the truck body returns to its specified height. Conversely, if the truck body moves up due to a removal of the loads, the lever arm rotates in an opposite direction and dumps the pressurized air from the airsprings into atmosphere across the leveling valve (air discharging), as shown in Figure 7a. In addition, there exists a dead band around the neutral position of the leveler arm, where no air flows for avoiding the valve chattering.

Page 11 of 25 


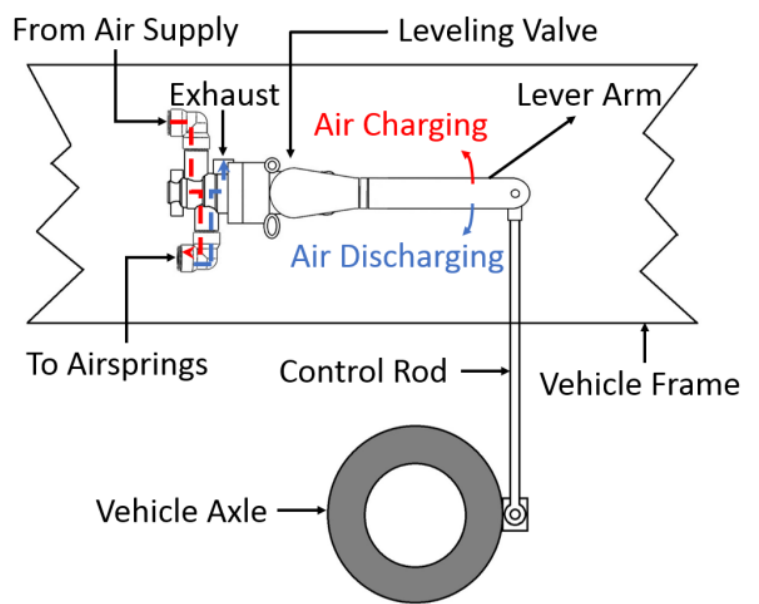

(a)

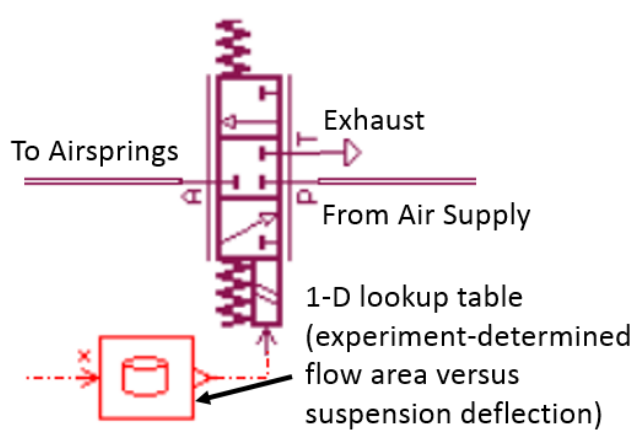

(b)

Figure 7. Schematics of (a) working process and (b) AMESim model of the leveling valve.

According to its working principle, the flow characteristics of the leveling valve are simulated by a three-position, three-port pneumatic valve model in AMESim, as shown in Figure $7 \mathrm{~b}$. Assuming isentropic flow, the mass flow rate $\left(\dot{m}_{L t}\right)$ of the level valve model is provided by Equations (6) and (7) as:

$$
\begin{aligned}
& \dot{m}_{L t}=A_{L} C_{q} P_{L i n} \sqrt{\frac{2 \gamma}{R T_{L i n}(\gamma+1)}}\left(\frac{2}{\gamma+1}\right)^{\frac{1}{\gamma-1}}\left[\frac{p_{L t}}{p_{L i n}} \leq\left(\frac{2}{\gamma+1}\right)^{\frac{\gamma}{\gamma-1}}\right], \\
& \dot{m}_{L t}=A_{L} C_{q} P_{L i n} \sqrt{\frac{2 \gamma}{R T_{L i n}(\gamma-1)}} \sqrt{\left(\frac{P_{L t}}{P_{L i n}}\right)^{\frac{2}{\gamma}}-\left(\frac{P_{L t}}{P_{L i n}}\right)^{\frac{\gamma+1}{\gamma}}}\left[\frac{p_{L t}}{p_{L i n}}>\left(\frac{2}{\gamma+1}\right)^{\frac{\gamma}{\gamma-1}}\right],
\end{aligned}
$$

where $P_{L i n}$ and $P_{L t}$ are, respectively, the upstream and downstream pressure; $T_{L i n}$ is the upstream temperature; $C_{q}$ is the flow coefficient; and $A_{L}$ is the flow area $[6,12]$. The change in flow area versus suspension deflection for the leveling valve considered for this study is determined experimentally [15], as shown in Figure 8a. It is important to note that various leveling valves used in practice have different flow areas (different flow characteristics). As such, the results in Figure 8 are limited to a specific leveling valve, although the approach presented here can be used broadly for penumatic suspension. The leveling valve model is compared with the experimental results in term of mass flow rate. Figure $8 \mathrm{~b}$ shows good agreement between the simulation and experimental data on the flow characteristics Page 12 of 25 
of the leveling valve for 50-psi supply pressure. The leveling valve for the BA suspension is designed to have a larger flow rate than the OE suspension in order to increase the dynamic bandwidth of the system, whereas the OE leveling valve is designed mainly for adjusting to load variation quasi-statically, the BA leveling valve is intended to change across the suspension dynamically.

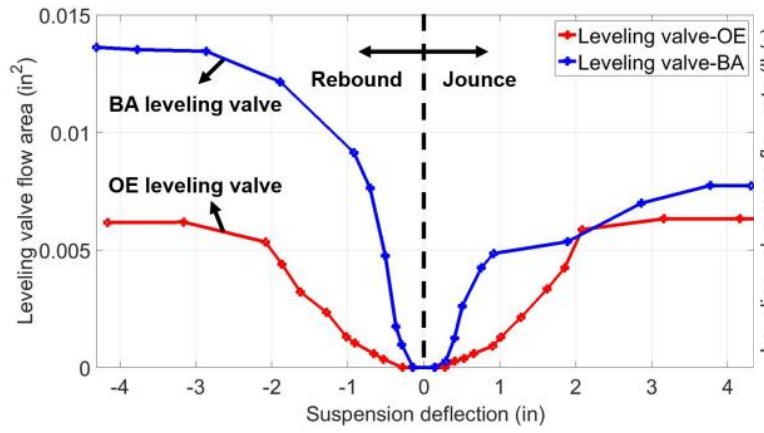

(a)

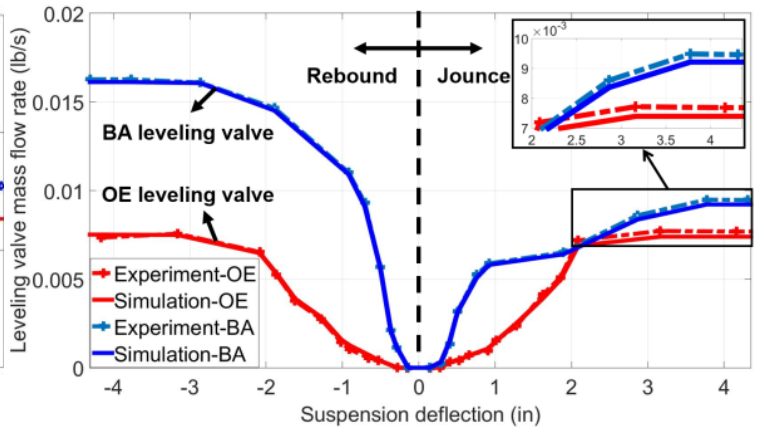

(b)

Figure 8. Effects of the suspension deflection on (a) flow area and (b) mass flow rate of leveling valves for the BA suspension and the $\mathrm{OE}$ suspension (end pressures are set to $50 \mathrm{psi}$ and $0 \mathrm{psi}$ ).

The failure of a fully-blocked leveling valve is modeled by setting the flow area to zero. When the control rod is bent, the straight-line distance from end to end is reduced. The failure regarding control rod bending can be simulated by shifting the flow characteristics of the leveling valve model. The shift is directly proportional to the reduction of rod's length due to bending. For the present study, rod length is shortened by 0.8 in, as shown in Figure 9.

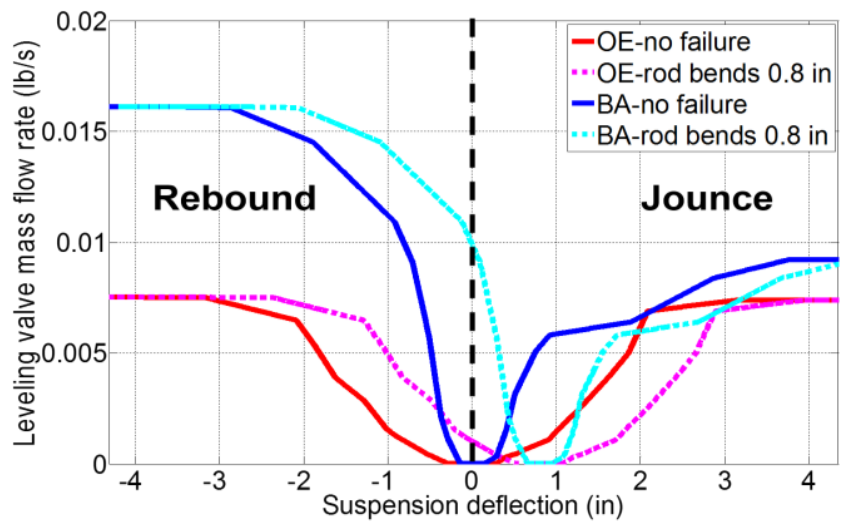

Figure 9. The effect of the control rod's bending on flow characteristics of the leveling valve.

Page 13 of 25 


\subsubsection{Pipe and T-junction Models}

The pneumatic pipe model in AMESim is used to simulate friction and compressive effects of transient air in a pipe. Since the pipe used in the pneumatic suspension (SAE J844 type 3B) contains two layers of piping with an internal layer of reinforcement for additional wall stiffness and strength, the increase of the pipe diameter under inner surface loading is negligible and assumed not included in the model. It is worth noting that a larger size pipe is used in the BA suspension for reduced air line resistance. Friction losses at the T- and L-junctions are negligible. Pressure and temperature of the T-junction are assumed to be the same at the other two ports, whereas the sum of the mass flow rate at all the three ports is zero.

Suspension system air leakage is modeled by adding an extra port with a pneumatic orifice, as shown in Figure 10. The downstream port of the orifice model is set to be the ambient pressure. The flow area of the orifice model depends on the rupture size due to failure. The suspension system is not affected if a small (pinhole) air leak occurs between the air tank and the leveling valve because of the large volume of air supply. If, however, the air leakage occurs at any connecting component between the leveling valve and the airsprings, it will change the air flow through the airsprings and affect the dynamic behavior of the suspension. For this failure analysis, significant air loss is assumed due to the failure at the T-junction connecting the leveling valve to the airsprings, with a rupture area of 0.00775 $\operatorname{in}^{2}\left(5 \mathrm{~mm}^{2}\right)$.

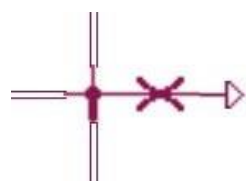

Figure 10. Pneumatic suspension air leakage model in AMESim.

\subsection{Semi-trailer Truck Multi-body Dynamic Model Integration}

By aligning the pneumatic component models (discussed earlier), BA and OE suspension system models are developed in AMEsim, as shown in Appendix A (Figure 18). The pneumatic suspension model is integrated into a WB-67 semi-truck model (a tractor and a Page 14 of 25 
53-ft semi-trailer) built in TruckSim using a co-simulation technique [16-17]. The cosimulation is created in a Simulink environment where the AMESim model and TruckSim model are coupled as two S-function modules, as shown in Appendix A (Figure 19). The TruckSim original airspring models on the tractor and trailer's axles are substituted with the AMESim pneumatic suspension model, as indicated in Figure 11. This truck dynamic model is capable of simulating and predicting the influence of the fluid dynamics of a pneumatic suspension on truck dynamics. The parameters for the pneumatic suspension model and truck dynamic model are listed in Table 2 of Appendix A.

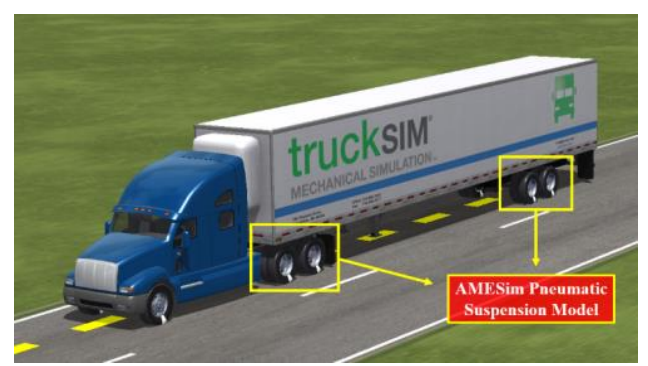

Figure 11. Tractor-semitrailer truck model in TruckSim with a 53-ft trailer.

\section{Simulation Analysis of the Suspension Failures}

This study will focus on the suspension failure occurring on the tractor's tandem axle only. The three representative failure cases, developed separately for the $\mathrm{OE}$ and $\mathrm{BA}$ suspensions on the tractor's tandem axle, include:

1. Fully-blocked leveling valve

2. Bent control rod

3. Suspension system air leakage

Figures $12 \mathrm{a}$ and $12 \mathrm{~b}$ show the failed suspension component for the cases considered for the $\mathrm{OE}$ and $\mathrm{BA}$ suspension systems.

Page 15 of 25 


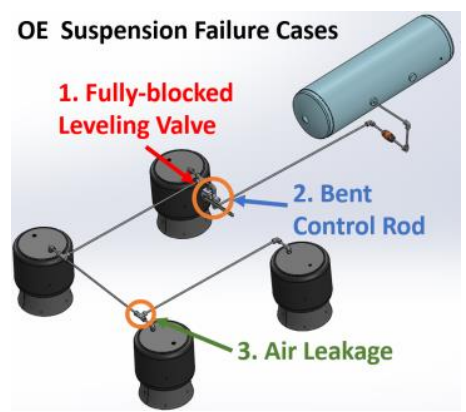

(a)

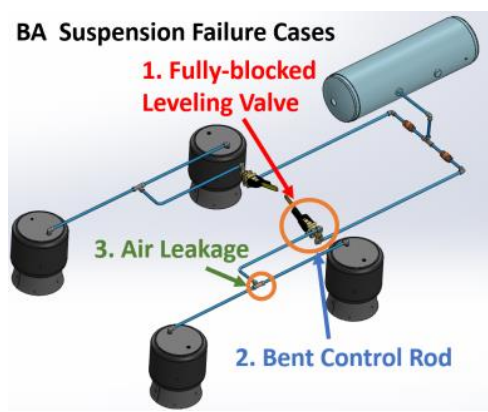

(b)

Figure 12. Failure cases of (a) the original equipment (OE) and (b) balanced (BA) suspensions on the semi-tractor tandem axle.

\subsection{Simulation Maneuver}

A steady-state maneuver is simulated to evaluate the vehicle response during straight-ahead and cornering driving while encountering suspension failure. The maneuver includes driving the truck in a straight path for $1650 \mathrm{ft}$, and then negotiating a circular track of 263$\mathrm{ft}$ radius at a constant speed of $30 \mathrm{mph}$, as shown in Figure 13. Because some failures cause an incline of the vehicle body to the failed side (right side), a left-hand turn is conducted to represent the worst-case scenario. All of the failures are assumed to happen at $\mathrm{t}=0$.

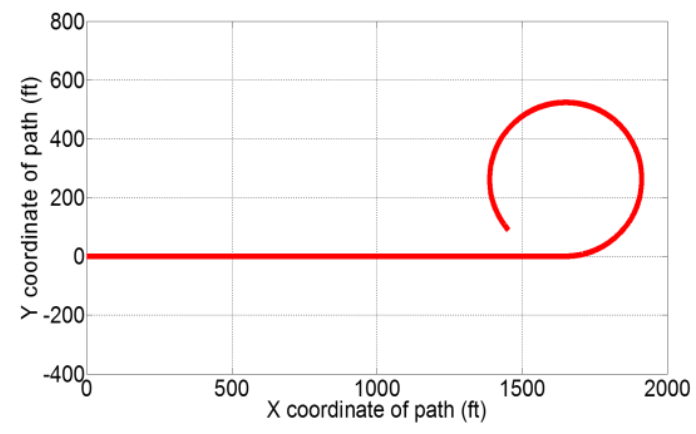

Figure 13. Steady-state straight-ahead and cornering path.

\subsection{Failure Case 1: Fully-blocked Leveling Valve}

The vehicle and suspension response parameters such as roll response, air flow at the leveling valve, airspring force, and deflection are obtained for both BA and OE suspensions to evaluate the effectiveness of the dual leveling valve control when suspension failure 
occurs. For the tandem arrangement on tractor drive and trailer axles, the front axle is used to represent the suspension dynamics.

Figure 14a presents a comparison of the mass flow rate at the leveling valve for BA and OE suspensions, respectively, when the leveling valve is fully blocked (i.e. no air flow through the valve). Although the blockage prevents air flow through the leveling valve, for the BA suspension, the valve on the un-failed side continues to allow air flow. As shown in Figure 14a, the truck body unbalanced at the beginning of the cornering maneuver $(\mathrm{t}=38 \mathrm{~s})$ results in air discharge from the left valve. Furthermore, the BA leveling valves on the trailer not affected by the failure provide a significantly large and well-regulated airflow control. This allows the jounce side to be charged while the rebound side is discharged, in order to balance the vehicle body. Consequently, as illustrated in Figure 14b, the truck with the BA suspension yields approximately $18 \%$ smaller peak roll angles than that with the OE suspension. This amounts to better body control and stability when confronted with the suspension failure. During the constant steering input, both the tractor and trailer experience a smaller roll angle than the OE suspension with the failed (blocked) leveling valve.

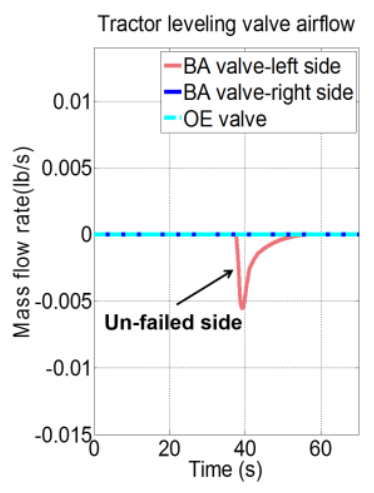

(a)

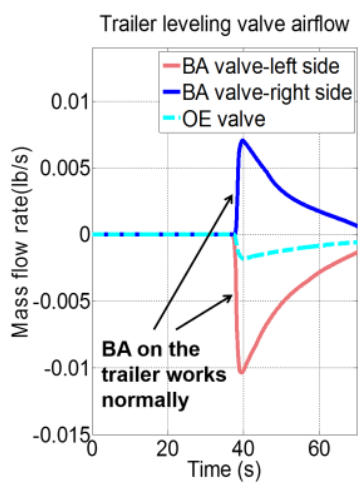

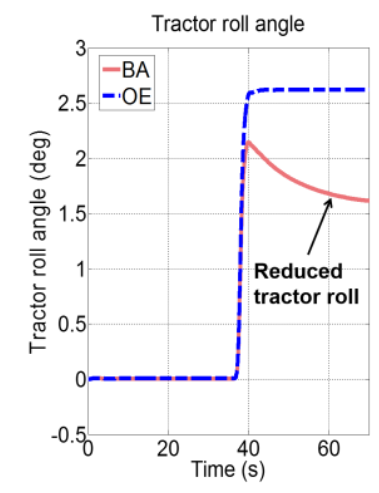

(b)

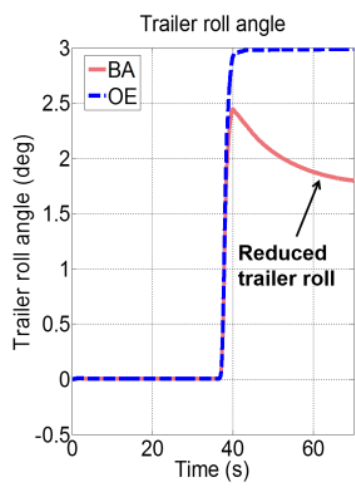

)

Page 17 of 25 


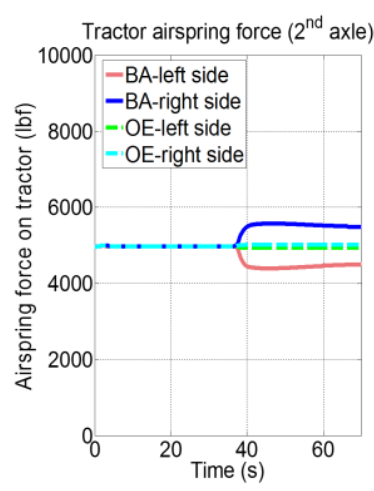

(c)

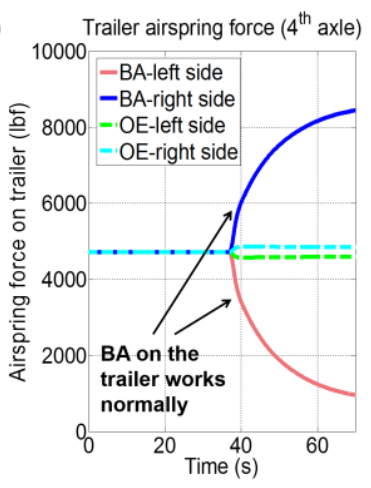

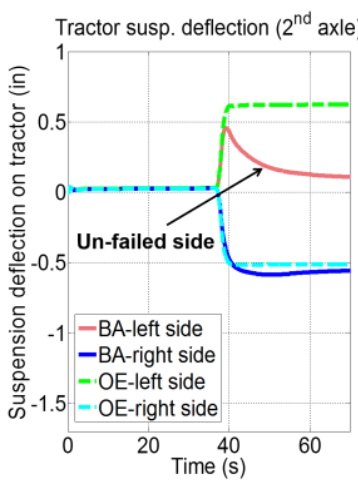

(d)

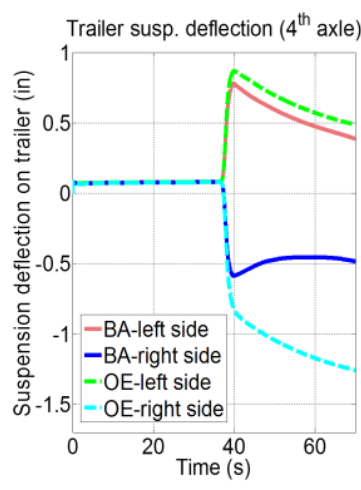

Figure 14. Simulation results for the failure case of the fully-blocked leveling valve: (a) mass flow rate at the leveling valve, (b) roll angle, (c) airspring force, and (d) suspension deflection.

Figures $14 \mathrm{c}$ and $14 \mathrm{~d}$ show the time response of airspring force and deflection for the BA and OE suspensions. For the BA suspension, although the leveling valve failure on the tractor suspension somewhat reduces the leveling capacity of the suspension, it continues to generate adequate balancing force to reasonably level the body. Interestingly, the trailer BA suspension assists with maintaining the tractor body leveled. For the OE suspension, however, a much smaller balancing force is observed for both tractor and trailer. Figure $14 \mathrm{~d}$ shows that the BA suspension on the side without failure experiences less deflection than the OE suspension and gradually returns to its ride height. A comparison of suspension deflection on the trailer indicates less suspension deflection by the BA suspension than the $\mathrm{OE}$ suspension. The reduction in trailer suspension deflection during cornering for the $\mathrm{OE}$ suspension (Figure 14d) is mainly due to the removal of air from the suspension, as it normally happens during sustained body roll for serially-plumbed airsprings. The results indicate that the BA suspension system does not become dysfunctional completely due to a blocked or failed leveling valve

\subsection{Failure Case 2: Bent Control Rod}

The second failure case considered is a bent control rod, as shown in Figure $2 \mathrm{~b}$. The failure starts at $\mathrm{t}=0$, when the bent control rod causes the leveling arm to move downward, purging air from the suspension. As a result of the suspension deflation, the vehicle body sinks until the leveling arm returns to the leveled position, as shown in Figure 15d. In particular, for 
the BA suspension, the leveled positions for the left and right sides are different due to unequal control rod length on the two sides. This causes a large unequal airspring force from side to side, as shown in Figure 15c. The uneven side-to-side airspring forces result in a tilted vehicle body, as indicated by the tractor and trailer roll angle in Figure 15b, before entering the turn $(\mathrm{t}<38 \mathrm{~s})$. In response to the steering maneuver, the BA suspension results in a lower roll angle than the OE suspension.

Figures $15 \mathrm{a}$ and $15 \mathrm{c}$ show that although the failure adversely affects the effectiveness of the BA suspension on the tractor, the trailer BA suspension maintains the side-to-side airspring forces that are needed to body roll. The trailer with the BA suspension components resists the roll for the tractor suspension failure to a certain extent. The simulation results also imply that even in the unlikely event that the suspension experiences a failure on both sides of the tractor (no air supply or dumped air), the BA suspension on the trailer is able to continue functioning until the failure is fixed.

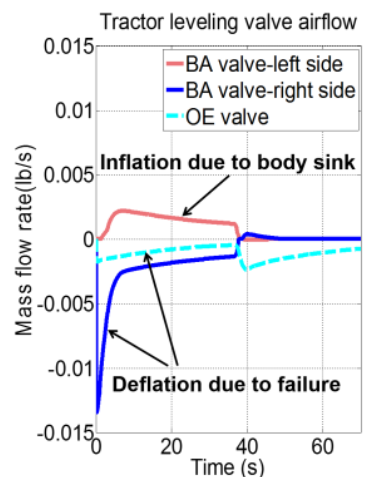

(a)

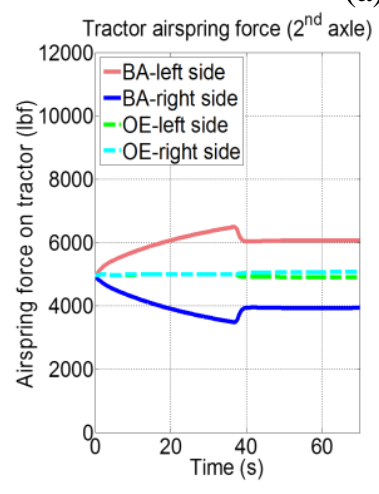

(c)
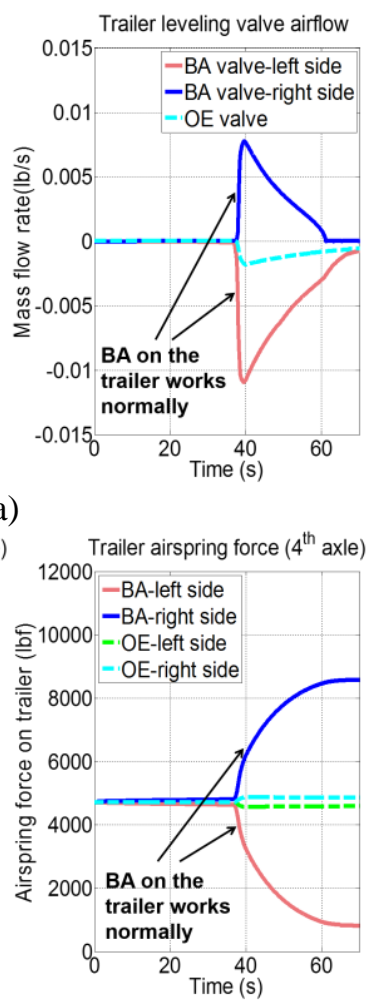
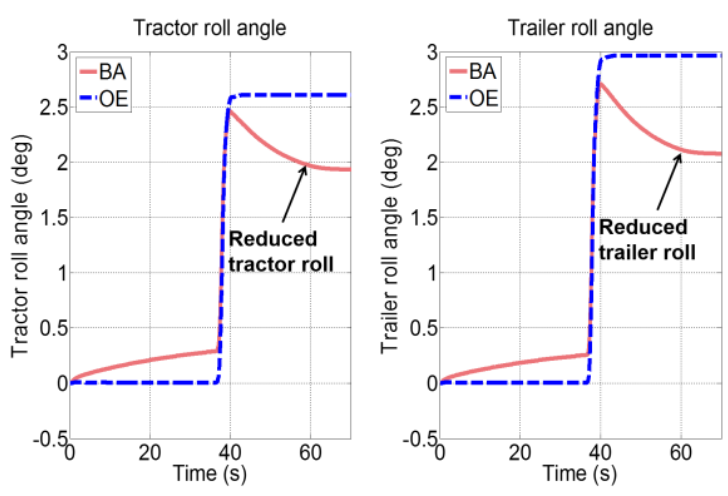

(b)
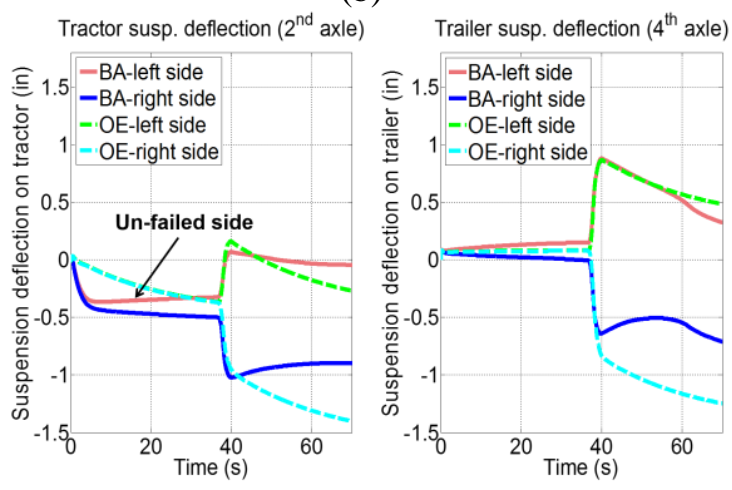

(d)

Page 19 of 25 
Figure 15. Simulation results for the failure of the control rod bending: (a) mass flow rate at the leveling valve, (b) roll angle, (c) airspring force, and (d) suspension deflection.

\subsection{Failure Case 3: Loss of Air Pressure due to Leakage}

Leakage within the pneumatic circuit can lead to depletion of air from the suspension, causing gradual deflection. The results in Figure 16 show air leakage, leveling valve flow rate, roll angle response, airspring force, and suspension deflection in the case of a gradual leak. Such a failure results in a reduction in ride height due to airspring deflection causing the leveler arm to rotate upward to supply air to the springs, as shown in Figure 16a. The reduction in ride height stops when the air supplied equals the air lost. As shown in Figure $16 \mathrm{~d}$, the reduction in OE suspension ride height (1.7 in) is significantly more than the BA suspension $(0.5 \mathrm{in})$. This is attributed to the lower flow rate for the $\mathrm{OE}$ suspension leveling valve. Similar to the control rod failure (failure case 2), the air loss due to leakage results in a slight inclination of the vehicle body to the failed side, as shown by the tractor and trailer roll angle in straight-ahead driving $(\mathrm{t}<38 \mathrm{~s})$ in Figure 16b. The simulation results in Figure 16b further show that in the turn ( $\mathrm{t}>38 \mathrm{~s})$, the BA suspension results in less roll than the OE suspension. For the BA suspension, the un-failed side maintains the ride height on that side of the vehicle. As shown in Figure 16c, the trailer BA suspensions exhibit significantly a larger restoring force than the OE suspension, as determined by the force differential between the suspension on the left and right sides.

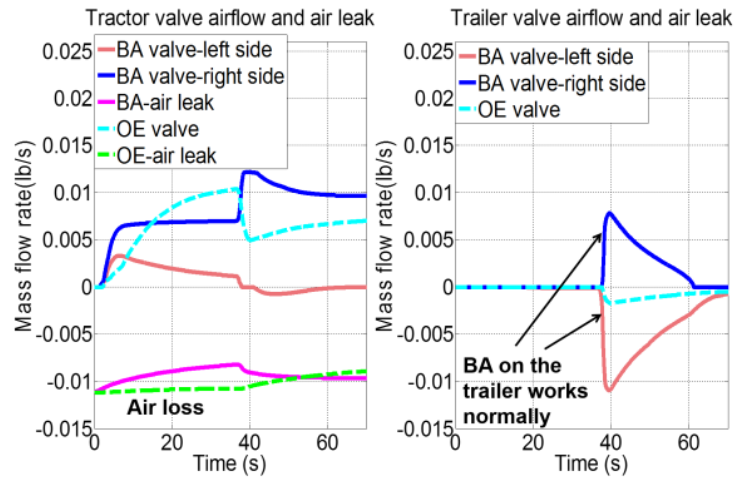

(a)

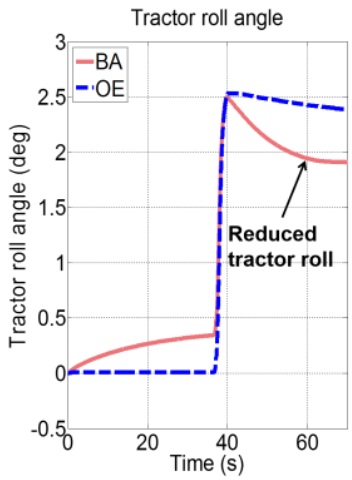

(b)

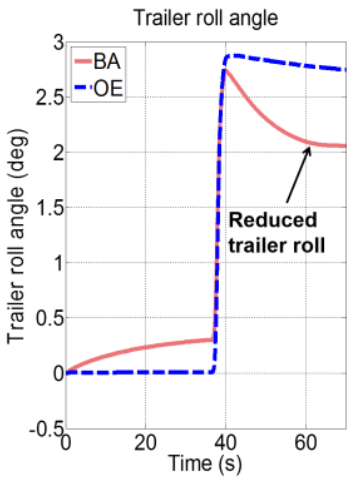

)

Page 20 of 25 


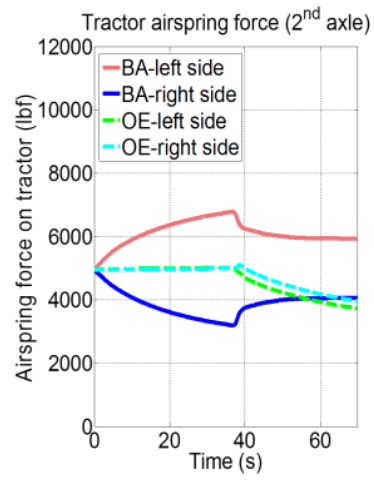

(c)

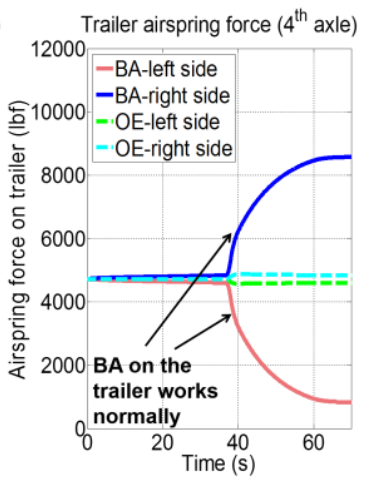

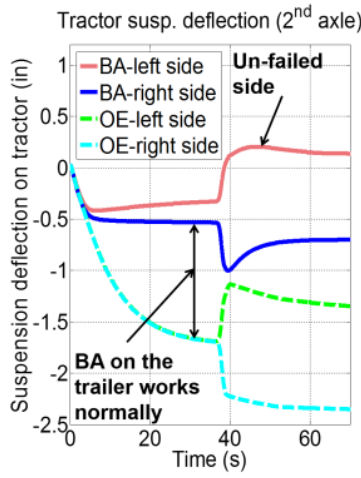

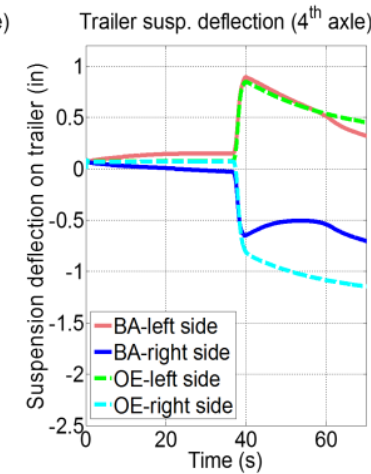

(d)

Figure 16. Simulation results for the failure case of air loss: (a) mass flow rate at the leveling valve and air leakage, (b) roll angle, (c) airspring force, and (d) suspension deflection.

\section{Conclusions}

The potential failure modes and their effects for truck pneumatic suspensions were simulated and studied. Three representative failure cases were selected for the study: 1) fully-blocked leveling valve, 2) control rod bending, and 3) air leakage in pipes and connecters due to puncture, wear, or damage during use. A multi-domain model that includes fluid dynamics of detailed pneumatic suspensions, semi-trailer truck dynamics, and the effect of the suspension failure was developed. The suspension dynamic response and vehicle body roll for a suspension with dual leveling valves-referred to as "balanced air" or "BA" suspension — was computed for a designed steer input. The results were compared with a suspension with a single leveling valve-referred to as "OE" suspension-for each failure case. The results overwhelmingly suggest that for the BA suspension the failure on one side of the suspension has a minimal effect on the roll dynamics of the vehicle, due to the failure redundancy offered by two leveling valves. The un-failed side works to keep the tractor body leveled in case of any suspension failures considered in this study. Interestingly, the study also indicates that the trailer suspensions further help with maintaining the body leveled, particularly when the trailer is also equipped with BA suspensions. In addition, in the event of air leakage, the BA suspension exhibited a better ability to maintain the vehicle ride height.

Page 21 of 25 


\section{References}

1. Cao, D., Song, X., Ahmadian, M., "Editors' Perspectives: Road Vehicle Suspension Design, Dynamics, and Control." Vehicle System Dynamics 49, no. 1-2, pp. 3-28, 2011.

2. Cole, D. J., "Fundamental Issues in Suspension Design for Heavy Road Vehicles." Vehicle System Dynamics 35, no. 4-5, pp. 319-360, 2001.

3. White, D. L., "Parametric Study of Leveling System Characteristics on Roll Stability of Trailing Arm Air Suspension for Heavy Trucks," SAE Technical Paper 2000-013480, 2000.

4. Richardson, S., Sandvik, A., Jones, C., Josevski N., Pei W., "The Comparative Testing of Single and Double Ride Height Control Valve Suspension Control System," 23rd ESV Conference, Seoul, Korea, May, 2013.

5. Hou, Y., Chen Y., and Ahmadian, M., "A Simulation-Based Study on the Improvement of Semi-Truck Roll Stability in Roundabouts," SAE Technical Paper 2016-01-8038, 2016.

6. Chen, Y., Ahmadian, M., and Peterson, A., "Pneumatically Balanced Heavy Truck Air Suspensions for Improved Roll Stability," SAE Technical Paper 2015-01-2749, 2015.

7. Vu, V. T., Sename, O., Dugard, L., Gáspár, P., "Enhancing Roll Stability of Heavy Vehicle by LQR Active Anti-roll Bar Control using Electronic Servo-valve Hydraulic Actuators." Vehicle System Dynamics 55, no. 9, pp. 1405-1429, 2017.

8. Dyadem, P., "Guidelines for Failure Mode and Effects Analysis for Automotive, Aerospace and General Manufacturing Industries," ISBN: 0-9731054-1-0.

9. Lee, S. J., "Development and Analysis of an Air Spring Model," International Journal of Automotive Technology, vol. 11, no. 4, pp. 471-479, 2011.

10. Docquier, N., Fisette, P., Jeanmart. H., "Model-based Evaluation of Railway Pneumatic Suspensions." Vehicle System Dynamics 46, no. S1, pp, 481-493, 2008.

11. Docquier, N., Fisette, P., Jeanmart. H., "Multiphysic Modelling of Railway Vehicles Equipped with Pneumatic Suspensions." Vehicle System Dynamics 45, no. 6, pp. 505524, 2007.

12. Yin, Z., Amir K., Dongpu C., Babak E., Konghui G.. "A New Pneumatic Suspension System with Independent Stiffness and Ride Height Tuning Capabilities," Vehicle System Dynamics 50, no. 12, pp. 1735-1746, 2012.

13. Quaglia, G., Massimo S., "Air Suspension Dimensionless Analysis and Design Procedure," Vehicle System Dynamics 35, no. 6, pp. 443-475, 2001.

Page 22 of 25 
14. Nieto, A. J., Morales, A. L., Gonzalez, A., Chicharro, J. M., Pintado, P., "An Analytical Model of Pneumatic Suspensions Based on an Experimental Characterization," Journal of Sound and Vibration, vol. 313, pp. 290-307, 2008.

15. Zhu, Z., "Flow Characterization and Redesign of Load-Leveling Valves for Improving Transient Dynamics of Heavy Truck Air Suspensions," Master thesis, Virginia Tech, 2016.

16. Kim, H., Lee, H., "Height and Leveling Control of Automotive Air Suspension System Using Sliding Mode Approach," Vehicular Technology, IEEE Transactions, vol. 60, no. 5, pp. 2027-2041, 2011.

17. Chang, F., Lu, Z., "Dynamic Model of an Air Spring and Integration into a Vehicle Dynamics Model," Proceedings of the Institution of Mechanical Engineers, Part D: Journal of Automobile Engineering 222, no. 10, pp. 1813-1825, 2008.

Page 23 of 25 


\section{Appendix A}

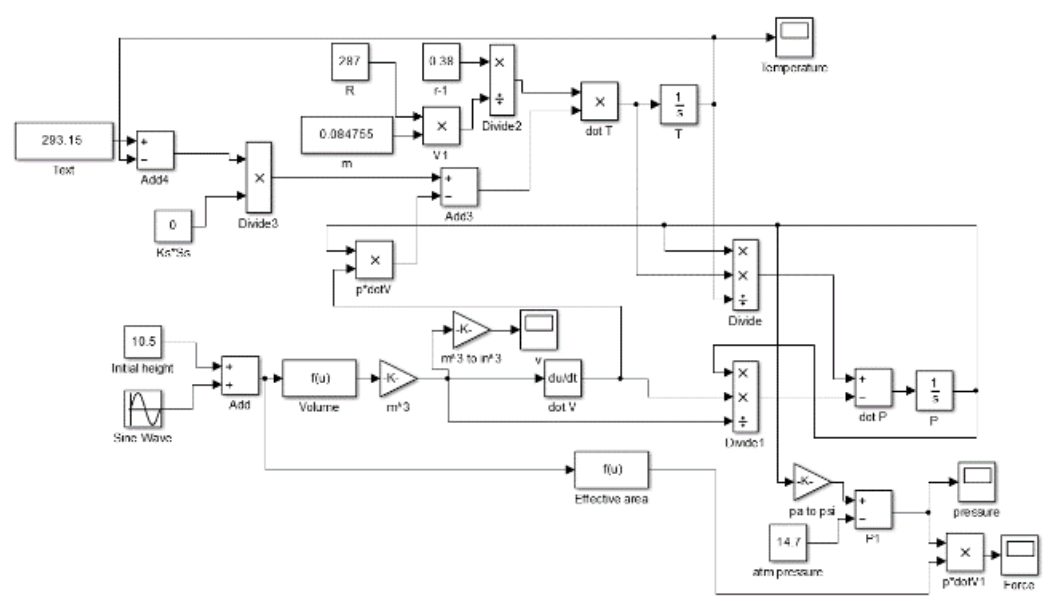

Figure 17. Airspring model developed in Simulink for verifying the AMESim airspring model.

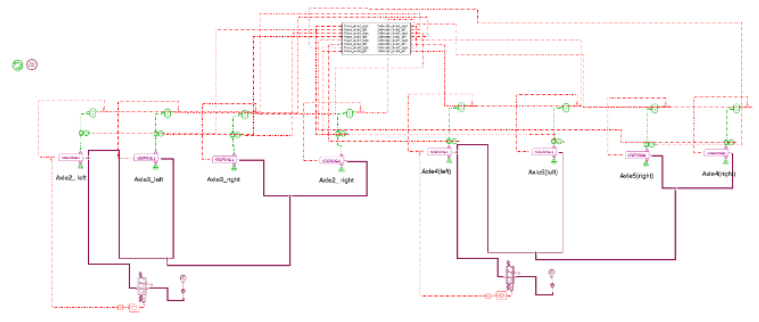

(a)

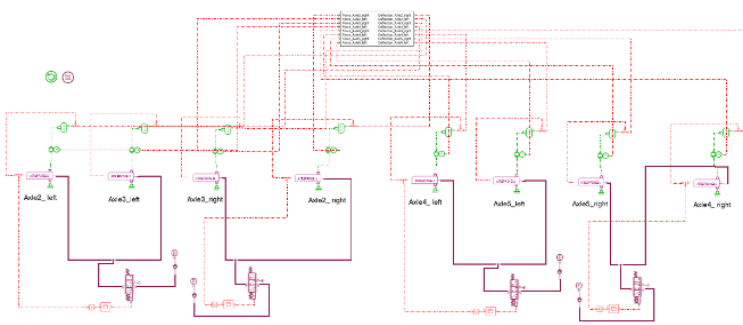

(b)

Figure 18. Tractor suspension system model in AMESim: (a) OE suspensions and (b) BA suspensions.

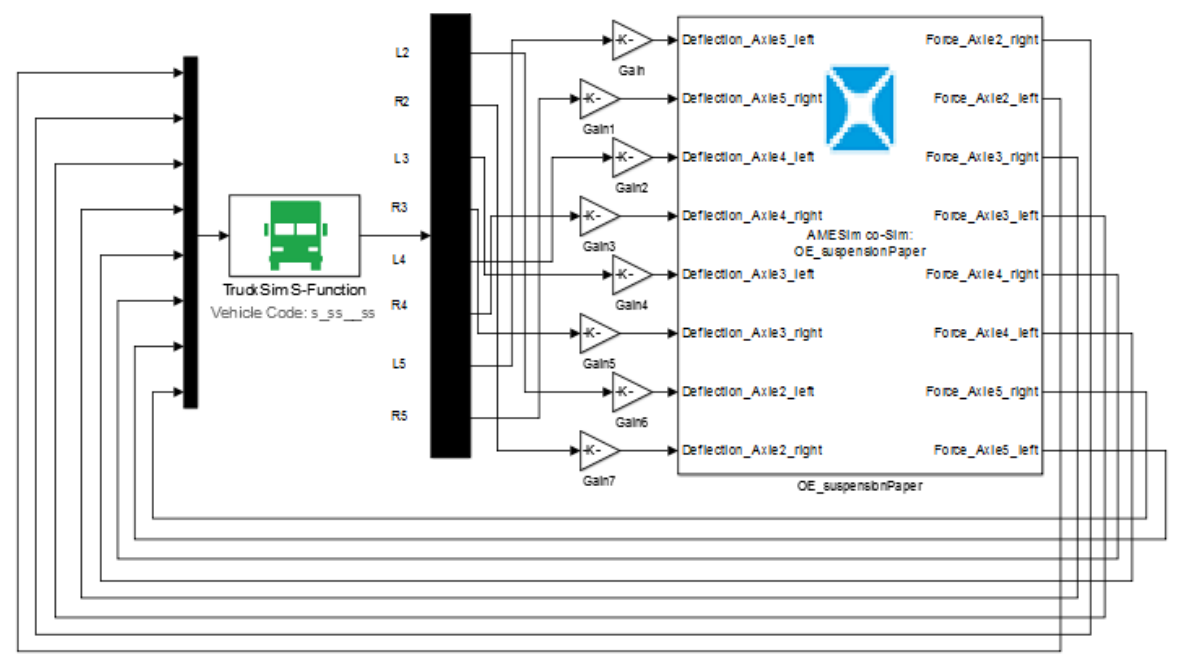

Figure 19. Co-simulation model in Simulink.

\section{Page 24 of 25}


Table 2. Parameters used for the truck dynamic simulation.

\begin{tabular}{|c|c|c|c|}
\hline Unit & Parameter & Value(English unit) & Value(SI unit) \\
\hline \multirow[t]{22}{*}{ Tractor } & Longitudinal distance from tractor CG to steering axle & 75.67 in & $1922.00 \mathrm{~mm}$ \\
\hline & Vertical distance from tractor CG to ground & 39.37 in & $1000.00 \mathrm{~mm}$ \\
\hline & Tractor body mass (sprung mass) & $14892.23 \mathrm{lb}$ & $6755.00 \mathrm{~kg}$ \\
\hline & Roll inertia of tractor body mass & $174714.78 \mathrm{lb} \cdot \mathrm{ft}^{2}$ & $7362.50 \mathrm{~kg} \cdot \mathrm{m}^{2}$ \\
\hline & Pitch inertia of tractor body mass & $551590.86 \mathrm{lb} \cdot \mathrm{ft}^{2}$ & $23244.10 \mathrm{~kg} \cdot \mathrm{m}^{2}$ \\
\hline & Yaw inertia of tractor body mass & $499365.08 \mathrm{lb} \cdot \mathrm{ft}^{2}$ & $21043.30 \mathrm{~kg} \cdot \mathrm{m}^{2}$ \\
\hline & Longitudinal distance from fifth wheel to steering axle & 198.93 in & $5052.82 \mathrm{~mm}$ \\
\hline & Distance from first drive axle to steering axle & 185.98 in & $4724.00 \mathrm{~mm}$ \\
\hline & Distance from second drive axle to steering axle & 237.75 in & $6038.85 \mathrm{~mm}$ \\
\hline & Track width of steering axle & 83.62 in & $2124.08 \mathrm{~mm}$ \\
\hline & Leaf spring stiffness on steering axle & $1427.54 \mathrm{lb} / \mathrm{in}$ & $250.00 \mathrm{~N} / \mathrm{mm}$ \\
\hline & Damping coefficient on steering axle & $1168.30 \mathrm{lb} /(\mathrm{ft} / \mathrm{s})$ & $17.05 \mathrm{kN} /(\mathrm{m} / \mathrm{s})$ \\
\hline & Lateral spacing between leaf springs on steering axle & 35.04 in & $890.00 \mathrm{~mm}$ \\
\hline & Lateral spacing between dampers on steering axle & 43.31 in & $1100.00 \mathrm{~mm}$ \\
\hline & Track width of front drive axle & 72.62 in & $1844.68 \mathrm{~mm}$ \\
\hline & Damping coefficient on front drive axle & $2124.18 \mathrm{lb} /(\mathrm{ft} / \mathrm{s})$ & $31.00 \mathrm{kN} /(\mathrm{m} / \mathrm{s})$ \\
\hline & Lateral spacing between airsprings on front drive axle & 30.00 in & $762.00 \mathrm{~mm}$ \\
\hline & Lateral spacing between dampers on front drive axle & 42.00 in & $1066.80 \mathrm{~mm}$ \\
\hline & Track width of rear drive axle & 72.62 in & $1844.68 \mathrm{~mm}$ \\
\hline & Damping coefficient on rear drive axle & $2124.18 \mathrm{lb} /(\mathrm{ft} / \mathrm{s})$ & $31.00 \mathrm{kN} /(\mathrm{m} / \mathrm{s})$ \\
\hline & Lateral spacing between airsprings on rear drive axle & 30.00 in & $762.00 \mathrm{~mm}$ \\
\hline & Lateral spacing between dampers on rear drive axle & 42.00 in & $1066.80 \mathrm{~mm}$ \\
\hline \multirow[t]{9}{*}{ Trailer } & Trailer tare mass (sprung mass) & $11358.22 \mathrm{lb}$ & $5152.00 \mathrm{~kg}$ \\
\hline & Trailer unsprung mass & $3042.38 \mathrm{lb}$ & $1380.00 \mathrm{~kg}$ \\
\hline & Vertical distance from kingpin to ground & 43.31 in & $1100.00 \mathrm{~mm}$ \\
\hline & Distance from first trailer axle to kingpin & 498.03 in & $12650.00 \mathrm{~mm}$ \\
\hline & Distance from second trailer axle to kingpin & 546.02 in & $13869.00 \mathrm{~mm}$ \\
\hline & Track width of trailer axles & 77.50 in & $1968.50 \mathrm{~mm}$ \\
\hline & Damping coefficient on trailer axles & $2124.18 \mathrm{lb} /(\mathrm{ft} / \mathrm{s})$ & $31.00 \mathrm{kN} /(\mathrm{m} / \mathrm{s})$ \\
\hline & Lateral spacing between airsprings on trailer axles & 39.37 in & $1000.00 \mathrm{~mm}$ \\
\hline & Lateral spacing between dampers on trailer axles & 31.50 in & $800.00 \mathrm{~mm}$ \\
\hline \multirow{7}{*}{$\begin{array}{l}\text { Pneumatic } \\
\text { Suspension }\end{array}$} & Air tank pressure & $120.00 \mathrm{psi}$ & $827370.88 \mathrm{~Pa}$ \\
\hline & Pipe inner diameter (BA) & 0.40 in & $10.16 \mathrm{~mm}$ \\
\hline & Pipe inner diameter $(\mathrm{OE})$ & 0.24 in & $6.00 \mathrm{~mm}$ \\
\hline & Gas constant & $287.00 \mathrm{~J} \cdot \mathrm{K} / \mathrm{kg}$ & $8.31 \mathrm{~m}^{2} \cdot \mathrm{Pa} /(\mathrm{K} \cdot \mathrm{mol})$ \\
\hline & Flow area of check valve & 0.16 in $^{2}$ & $100.00 \mathrm{~mm}^{2}$ \\
\hline & Tractor airspring initial height & 11.00 in & $254.00 \mathrm{~mm}$ \\
\hline & Trailer airspring initial height & 8.00 in & $203.20 \mathrm{~mm}$ \\
\hline
\end{tabular}

Page 25 of 25 